\title{
Complement activity is associated with disease severity in multifocal motor neuropathy
}

\section{OPEN}

Lotte Vlam, MD

Elisabeth A. Cats, MD,

$\mathrm{PhD}$

Oliver Harschnitz, MD

Marc D. Jansen

Sanne Piepers, MD, PhD

Jan Herman Veldink,

$\mathrm{MD}, \mathrm{PhD}$

Hessel Franssen, MD,

$\mathrm{PhD}$

Abraham C.J. Stork, MD

Erik Heezius

Suzan H.M. Rooijakkers, $\mathrm{PhD}$

Bjorn L. Herpers, MD Jos A. van Strijp, $\mathrm{PhD}$

Leonard H. van den Berg,

$\mathrm{MD}, \mathrm{PhD}$

W. Ludo van der Pol, $\mathrm{MD}, \mathrm{PhD}$

Correspondence to

Dr. van der Pol:

w.l.vanderpol@umcutrecht.nl

Supplemental data at Neurology.org/nn

\section{ABSTRACT}

Objective: To investigate whether high innate activity of the classical and lectin pathways of complement is associated with multifocal motor neuropathy (MMN) and whether levels of innate complement activity or the potential of anti-GM1 antibodies to activate the complement system correlate with disease severity.

Methods: We performed a case-control study including 79 patients with MMN and 79 matched healthy controls. Muscle weakness was documented with Medical Research Council scale sum score and axonal loss with nerve conduction studies. Activity of the classical and lectin pathways of complement was assessed by ELISA. We also determined serum mannose-binding lectin (MBL) concentrations and polymorphisms in the MBL gene (MBL2) and quantified complementactivating properties of anti-GM1 IgM antibodies by ELISA.

Results: Activity of the classical and lectin pathways, MBL2 genotypes, and serum MBL concentrations did not differ between patients and controls. Complement activation by anti-GM1 IgM antibodies was exclusively mediated through the classical pathway and correlated with antibody titers $(p<0.001)$. Logistic regression analysis showed that both high innate activity of the classical pathway of complement and high complement-activating capacity of anti-GM1 IgM antibodies were significantly associated with more severe muscle weakness and axonal loss.

Conclusion: High innate activity of the classical pathway of complement and efficient complementactivating properties of anti-GM1 IgM antibodies are determinants of disease severity in patients with MMN. These findings underline the importance of anti-GM1 antibody-mediated complement activation in the pathogenesis and clinical course of MMN. Neurol Neuroimmunol Neuroinflamm 2015;2:e119; doi: 10.1212/NXI.0000000000000119

\section{GLOSSARY}

BSA = bovine serum albumin; CMAP = compound motor action potential; dig = digoxigenin; GBS = Guillain-Barré syndrome; GVBS = gelatin veronal-buffered saline; HPS = human pooled serum; IVIg = IV immunoglobulin; MAC = membrane attack complex; $\mathbf{M B L}=$ mannose-binding lectin; $\mathbf{M M N}=$ multifocal motor neuropathy; $\mathbf{M R C}=$ Medical Research Council; $\mathbf{O D}=$ optical density; PBS = phosphate-buffered saline; SNP = single nucleotide polymorphism.

Multifocal motor neuropathy (MMN) is a chronic polyneuropathy characterized by asymmetric predominantly distal limb weakness, conduction block, and the presence of anti-GM1 IgM antibodies in approximately half of patients. ${ }^{1}$ The frequent presence of anti-GM1 antibodies and the response to treatment with IV immunoglobulin (IVIg) suggest an immune-mediated etiology. ${ }^{2,3}$

The hypothesis that anti-GM1 antibodies play an important role in MMN pathogenesis is supported by similarities with the axonal variants of Guillain-Barré syndrome (GBS) ${ }^{4,5}$ and animal models. ${ }^{6,7}$ Rabbits developed anti-GM1 antibodies and flaccid paresis after immunization with GM1. Their IgG reacted with rabbit peripheral nerve, ${ }^{8}$ and only anti-GM1 antibodies from rabbits with neuropathy activated complement. ${ }^{9}$ Deposition of complement components and anti-GM1 IgG antibodies in (para)nodal regions, where GM1 is abundantly expressed, ${ }^{10,11}$

From Brain Center Rudolf Magnus (L.V., E.A.C., O.H., M.D.J., S.P., J.H.V., H.F., A.C.J.S., L.H.v.d.B., W.L.v.d.P.), Department of Neurology and Department of Medical Microbiology (E.H., S.H.M.R., J.A.v.S.) University Medical Center Utrecht, the Netherlands; and Regional Public Health Laboratory Kennemerland (B.L.H.), Haarlem, the Netherlands.

Funding information and disclosures are provided at the end of the article. Go to Neurology.org/nn for full disclosure forms. The Article Processing Charge was paid by University Medical Center Utrecht, the Netherlands.

This is an open access article distributed under the terms of the Creative Commons Attribution-NonCommercial-NoDerivatives License 4.0 (CC BY-NC-ND), which permits downloading and sharing the work provided it is properly cited. The work cannot be changed in any way or used commercially. 
caused disruption of sodium channel clustering at the nodes of Ranvier. ${ }^{12}$ This mechanism may underlie conduction block, which is also a characteristic of GBS. ${ }^{4}$

Few studies have addressed pathogenic mechanisms and the role of anti-GM1 IgM antibodies in patients with MMN. Anti-GM1 IgM antibodies in sera from patients with MMN, but not from relevant disease controls, activate complement in vitro, ${ }^{13,14}$ and IVIg may exert beneficial effects by attenuation of systemic complement activity and antibodymediated deposition of complement. ${ }^{13,14}$

Differences in innate complement activity determine susceptibility to and outcome of several inflammatory disorders, possibly including GBS. ${ }^{15}$ We therefore investigated whether high innate activity of the classical and lectin pathways of complement, which are activated by antibody complexes, is a risk factor for MMN or unfavorable outcome and compared innate classical and lectin pathway activity, mannose-binding lectin (MBL) serum concentrations, and MBL2 genotypes between patients and controls. We also investigated whether the complementactivating capacity of anti-GM1 IgM antibodies is associated with disease severity.

METHODS Patients and controls. Seventy-nine patients with MMN and 79 sex- and age-matched ( \pm 5 years) healthy controls were included in this study. All participants were Dutch Caucasian and all patients fulfilled the diagnostic criteria for MMN. ${ }^{16}$ Muscle strength was examined bilaterally by the same investigator (E.A.C.) in all patients using the Medical Research Council (MRC) scale ranging from 0 (no movement) to 5 (normal). Eleven arm muscle groups and 7 leg muscle groups were tested, and the MRC sum score was calculated accordingly (maximum 180). Axonal loss was assessed by scoring decreased distal compound muscle action potential (CMAP) (amplitude below the lower limit of normal) for the median, ulnar, radial, musculocutaneous, peroneal, and tibial nerves on both sides. ${ }^{17}$ Anti-GM1 IgM antibody titers were determined with ELISA. ${ }^{3}$

Standard protocol approvals, registrations, and patient consents. The study protocol was approved by the Medical Ethical Committee of the University Medical Center Utrecht and all participants gave written informed consent.

Sera and DNA samples. Serum samples were obtained from all patients and stored at $-80^{\circ} \mathrm{C}$ before use. Seventy patients with MMN (89\%) received IVIg maintenance treatment at the time of blood sampling. Serum IgG levels were determined in all samples using nephelometric techniques (IMMAGE, Beckman Coulter, Brea, CA). Genomic DNA was isolated from whole blood samples using standard methodology. DNA samples could be obtained for 75 patients and 71 controls.

MBL concentrations and genotyping of MBL2. Serum concentration of the multimeric MBL protein was determined with an ELISA (Sanquin, Amsterdam, the Netherlands). The $\mathrm{X} / \mathrm{Y}$ promoter polymorphism (rs7096206) and the 3 single nucleotide polymorphisms (SNPs) in exon 1 (wild-type "A" and variants "O" rs5030737, rs1800450, and rs1800451) of the MBL2 gene were determined using a previously described denaturing gradient gel electrophoresis assay in a nested PCR protocol. ${ }^{18,19}$ Genotypes $0 / 0$ and XA/0 were considered MBL-deficient, and genotypes YA/0, XA/XA, XA/YA, and YA/YA were considered MBL-sufficient, with the YA/YA genotype related to the highest lectin pathway activity. ${ }^{20,21}$

Activity of lectin and classical pathways of complement. The innate activity of the lectin and classical pathways of complement was determined using a previously published ELISA protocol with minor modifications. ${ }^{22,23}$ In short, ELISA plates were either coated with mannan $(10 \mu \mathrm{g} / \mathrm{mL}$, Sigma-Aldrich, St. Louis, $\mathrm{MO})$ for the lectin pathway and human $\operatorname{IgM}(3 \mu \mathrm{g} / \mathrm{mL}$, Calbiochem, San Diego, CA) for the classical pathway or left uncoated. For each sample a corrected optical density (OD) was calculated (OD of coated wells minus OD of noncoated wells). Serum samples diluted $1 / 100$ in gelatin veronal-buffered saline $(\mathrm{GVBS})++$ (veronal containing $0.05 \mathrm{mM} \mathrm{CaCl}_{2}$, $0.025 \mathrm{mM} \mathrm{MgCl}_{2}$, and $0.1 \%$ gelatin; $\mathrm{pH}$ 7.4-7.6) were added in triplicate. To block any contribution of the classical pathway to the complement activation by mannan, anti-human $\mathrm{C} 1 \mathrm{q}$ (Sanquin) was added to the serum during assessment of the lectin pathway activity. ${ }^{24}$ To correct for day-to-day variation and variation between the plates, human pooled serum (HPS) from 10 healthy donors was included in each experiment. Lectin and classical pathway activity was expressed relative to the activity of the HPS (corrected OD sample/corrected OD HPS $\times 100$ ).

Complement-activating capacity of anti-GM1 IgM antibodies. We measured complement activation by IgM antiGM1 antibodies with a previously described ELISA with some modifications. ${ }^{13}$ Plates were coated with $0.5 \mu \mathrm{g}$ GM1 in methanol (Alexis, Kordia Life Sciences, Leiden, the Netherlands) or with human plasma IgM $(3 \mu \mathrm{g} / \mathrm{mL}$ in $0.1 \mathrm{M} \mathrm{Na}$-carbonate buffer, $\mathrm{pH}$ 9.6, Calbiochem) as a positive control. Wells saturated with phosphate-buffered saline (PBS) 1\% bovine serum albumin (BSA) served as a control for nonspecific binding. Heat-inactivated patient sera diluted 1/100 in PBS 1\% BSA were added in triplicate. Pooled healthy donor serum diluted 2/100 in GVBS++ was added as a complement source. C3 complement binding was detected by adding digoxigenin (dig)-labeled mouse anti-C3c "WM1" antibody (ATCC, $0.1 \mu \mathrm{g} / \mathrm{mL}$ in $1 \%$ BSA-PBS) followed by incubation with peroxidase-labeled anti-dig antibody (Roche Diagnostics, Indianapolis, IN). C5b-9 complement binding was detected by adding mouse anti-C $5 \mathrm{~b}-9(1 \mu \mathrm{g} / \mathrm{mL}$ in $1 \%$ BSA-PBS, Santa Cruz Biotechnology Inc., Dallas, TX) followed by incubation with anti-mouse IgG-peroxidase $(80 \mathrm{ng} / \mathrm{mL}$ in $1 \%$ BSA-PBS, Jackson ImmunoResearch Laboratories, Inc., Baltimore, MD). All incubation volumes were $70 \mu \mathrm{L}$.

Statistical analysis. Pearson $\chi^{2}$ test was used to compare $M B L 2$ genotypes between patients and controls. Mann-Whitney $U$ test was used to compare age, MBL concentrations, lectin and classical pathway activity, and $\operatorname{IgG}$ concentrations between patients and controls, and MBL concentration and classical and lectin pathway activity between patients on IVIg maintenance treatment and IVIg-naive patients. Correlations of MBL2 genotypes with MBL concentration and lectin pathway activity were calculated with the Kruskal-Wallis test. Spearman rank correlation coefficient was used to investigate the association of MBL concentration with lectin pathway activity, IgG 


\begin{tabular}{|lll|}
\hline Table $1 \quad$ Characteristics of patients and controls & \\
& Patients $(\mathbf{n}=79)$ & Controls $(\mathbf{n}=79)$ \\
Age at inclusion, $y$ & $52(27-78)$ & 53 (27-78) \\
Sex, male & $61(77)$ & $60(76)$ \\
Age at onset, $y$ & $40(22-66)$ & - \\
Site of onset & & - \\
Hand & $45(57)$ & \\
Upper arm & $4(5)$ & - \\
Foot & $30(38)$ & \\
Anti-GM1 antibodies & $34(43)$ & - \\
$\geq 1: 400$ & & - \\
Conduction block & $65(82)$ & - \\
Definite & $14(18)$ & - \\
Probable & $69(87)$ & - \\
Axonal loss present & $2(0-10)$ & - \\
Degree of axonal loss & $165(108-179)$ & - \\
MRC scale sum score & $4(0-9)$ & - \\
ODSS & & \\
\hline
\end{tabular}

Abbreviations: MRC = Medical Research Council; ODSS = overall disability sum score. Data are median (range) or number (\%).

concentration with lectin and classical pathway activity, and C3b and C5b-9 deposition with anti-GM1 IgM titers.

To identify whether activity of the complement pathways contributed to disease severity, we used multinomial logistic regression analysis with weakness (MRC sum score) and axonal loss (number of nerves with decreased distal CMAP) as outcome measures. We divided patients into quartiles based on degree of weakness and axon loss. Patients with minor abnormalities (first quartile) were compared with patients with mild, moderate, or severe disease course (second, third, and fourth quartiles, respectively). Multivariate analysis was performed to investigate whether MBL2 genotypes, MBL concentration, classical and lectin pathway activity, and GM1 complement-activating capacity were determinants of outcome. Sex, conduction block (CMAP area reduction $30 \%-50 \%$ vs CMAP area reduction over $50 \%$ ), age at onset, number of years untreated (disease duration without IVIg treatment), and IgG concentration were included as covariates. We used SPSS for Windows version 20 (Chicago, IL) for all statistical analysis. A $p$ value $<0.05$ was considered statistically significant.

RESULTS Patients and controls. Characteristics of patients and controls are shown in table 1 .

MBL2 genotypes and MBL serum concentrations. MBL2 SNPs were in Hardy-Weinberg equilibrium. There were no differences in genotype distributions between 75 patients and 71 controls $(p=0.17)$ (table 2). Frequencies of genotypes associated with high MBL activity (YA/YA and YA/XA) were similar between patients (63\%) and controls (54\%) $(p=0.26)$.

The median MBL serum concentration was 1,550 $\mathrm{ng} / \mathrm{mL}$ (range $40-4,000 \mathrm{ng} / \mathrm{mL}$ ) in patients and $1,760 \mathrm{ng} / \mathrm{mL}$ (range $20-4,000 \mathrm{ng} / \mathrm{mL}$ ) in controls $(p=0.97)$. The MBL concentration correlated with the MBL2 haplotype in patients and controls $(p<$ 0.001) (table 2, figure e-1 at Neurology.org/nn).

Lectin and classical pathway activity in patients and controls. Figure 1 shows the activity of the lectin and classical pathways of 79 patients with $\mathrm{MMN}$ and

Table 2 MBL2 genotype, MBL concentration, and lectin pathway activity in patients with MMN and controls

$\begin{array}{llll}\begin{array}{l}\text { Genotype } \\ \text { Patients }(\mathbf{n}=75)\end{array} & \begin{array}{l}\text { MBL concentration, } \\ \mathbf{n g} / \mathrm{mL}(\text { range) }\end{array} & \begin{array}{l}\text { Lectin pathway } \\ \text { activity, \% (range) }\end{array} \\ \text { YA/YA } & 29(39) & 3,120(900-4,000) & 147(0-329) \\ \text { YA/XA } & 18(24) & 1,900(620-3,400) & 165(0-319) \\ \text { YA/0 } & 15(20) & 520(140-1,300) & 14(0-176) \\ \text { XA/XA } & 4(5) & 580(140-1,060) & 6(0-63) \\ \text { XA/0 } & 4(5) & 90(40-160) & 0(0-4) \\ \text { O/0 } & 5(7) & 80(60-140) & 0(0-0) \\ \text { Controls }(\mathbf{n}=71) & & & 206(0-340) \\ \text { YA/YA } & 19(27) & 3,540(1,640-4,000) & 178(16-347) \\ \text { YA/XA } & 19(27) & 2,180(660-3,600) & 29(0-200) \\ \text { YA/0 } & 23(32) & 580(200-2,200) & - \\ \text { XA/XA } & 0 & - & 2(0-6) \\ \text { XA/0 } & 4(6) & 70(20-410) & 0(0-6) \\ \text { O/0 } & 6(8) & 40(20-80) & \end{array}$

Abbreviations: $\mathrm{MBL}=$ mannose-binding lectin; $\mathrm{MMN}=$ multifocal motor neuropathy

${ }^{a}$ In relation to activity of pooled serum from 10 healthy donors (set at $100 \%$ ). There were no differences in MBL2 genotype distributions $(p=0.17)$, median MBL serum concentration $(p=0.97)$, and median lectin pathway activity $(p=0.37)$ between patients and controls. 
Figure 1 Classical pathway and lectin pathway activity in patients with multifocal motor neuropathy and controls
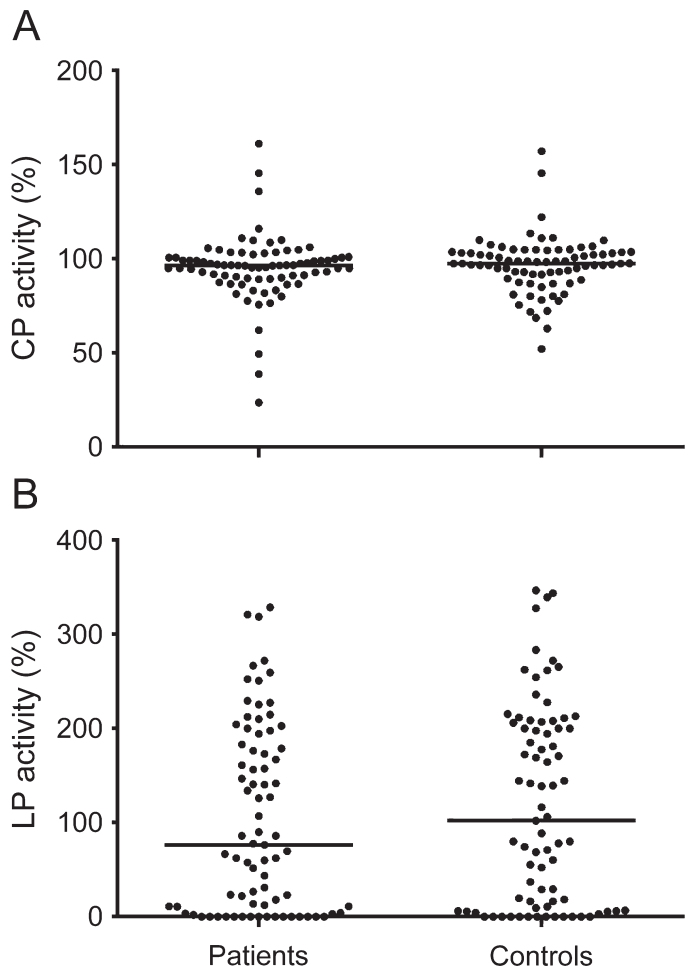

Classical pathway (CP) activity (A) and lectin pathway (LP) activity (B) was expressed relative to the activity of the human pooled serum (\%). Bars represent median $\mathrm{CP}$ and LP activity.

79 controls relative to the activity of pooled serum from 10 healthy donors. The median lectin pathway activity was 77\% (range 0\%-329\%) in patients with MMN and $96 \%$ (range $0 \%-347 \%$ ) in controls $(p=$ $0.37)$. The lectin pathway activity correlated with the MBL2 haplotype $(p<0.001)$ and the MBL concentration $\left(r_{\mathrm{s}}=0.77, p<0.001\right)$ in patients with MMN and controls (table 2). The median classical pathway activity was $96 \%$ (range 24\%-161\%) in patients with MMN and 98\% (range 52\%-157\%) in controls ( $p=$ 0.32 ). Lectin or classical pathway activity did not correlate with IgM anti-GM1 antibody titers. Median lectin or classical pathway activity did not differ between patients with or without anti-GM1 IgM antibody titers $\geq 1: 400$ (figure e-2).

Lectin and classical pathway activity and association with IgG concentration. Seventy patients (89\%) were on IVIg maintenance treatment at the time of blood withdrawal. Median IgG concentration in the patients on IVIg treatment was $19 \mathrm{~g} / \mathrm{L}$, compared with $16 \mathrm{~g} / \mathrm{L}$ in the 9 patients in whom blood was taken before treatment $(p=0.45)$. Serum IgG concentrations were higher in patients than in controls (median $18 \mathrm{~g} / \mathrm{L}$ vs $11 \mathrm{~g} / \mathrm{L}, p<0.001)$. Complement activity did not differ between the patients on treatment and the IVIg-naive patients (median classical pathway activity $96 \%$ vs $97 \%, p=0.58$; lectin pathway activity $77 \%$ vs $70 \%, p=0.87)$. There was no correlation between IgG concentration and classical pathway activity $(p=0.23)$ or lectin pathway activity $(p=0.19)$ in patients with MMN (figure e-3).

Complement-activating capacity of anti-GM1 IgM antibodies. Figure 2A shows the complement activation by anti-GM1 IgM antibodies. Deposition of complement activation products $\mathrm{C} 3 \mathrm{~b}$ and the terminal pathway complex C5b-9 (membrane attack complex $[\mathrm{MAC}]$ ) correlated with anti-GM1 IgM antibody titers (C3b $r_{\mathrm{s}}=0.73, p<0.001$; C5b-9 $\left.r_{\mathrm{s}}=0.71, p<0.001\right)$. As expected, serum from the 27 patients without detectable anti-GM1 IgM antibodies did not activate the complement system. Compared to the OD values of these anti-GM1 IgM antibody-negative patients, median $\mathrm{C} 3 \mathrm{~b}$ and $\mathrm{C} 5 \mathrm{~b}-9$ OD values of the patients with GM1 reactivity were higher in samples with anti-GM1 IgM antibody titers of $\geq 1: 400(p<0.001)$.

Deposition of complement factors C3b and C5b-9 showed close correlation $\left(r_{\mathrm{s}}=0.93, p<0.001\right.$, figure 2B). C3b and C5b-9 deposition was abrogated after addition of anti-C1q antibody or the calcium scavenger ethylene glycol tetraacetic acid (data not shown), suggesting that complement activation was triggered through the classical pathway of complement.

Antibodies, complement activity, and disease severity. We investigated the association of complement activity and disease severity in a multivariate model with sex, conduction block, age at onset, number of years without IVIg treatment, and IgG concentration as covariates. We used muscle weakness and axon loss, which is an important determinant of disability, 2,25 as the outcome measures. We defined quartiles of weakness (MRC sum score) and axon loss (number of nerves with a decreased distal CMAP). Weakness was minor in 21 patients (173-179), mild in 20 patients (165-172), moderate in 19 patients (146$164)$, and severe in 19 patients (108-145). Results from extensive nerve conduction studies to score axon loss were available for 77 patients. Axon loss was minor in 24 patients (0-1), mild in 15 patients (2), moderate in 21 patients (3-4), and severe in 17 patients (5-10). Patients with minor weakness or axon loss were compared with patients with mild, moderate, or severe disease course.

Multinomial logistic regression analysis showed that innate classical pathway activity was higher in patients with mild, moderate, and severe weakness compared with those with minor weakness $(p=0.006$, $p=0.02$, and $p=0.003$, respectively). A similar trend was seen for the association of innate classical 
Figure 2 Activation of the complement system by IgM anti-GM1 antibodies

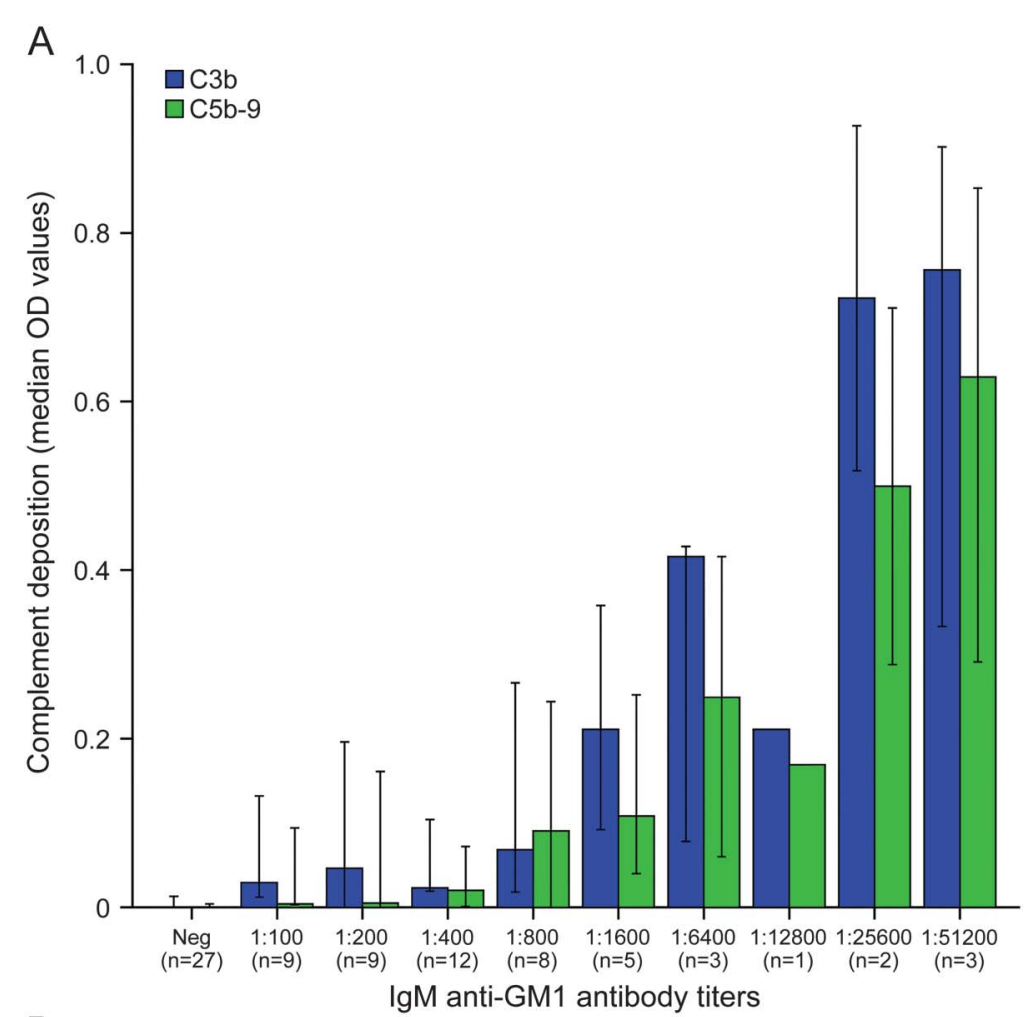

B

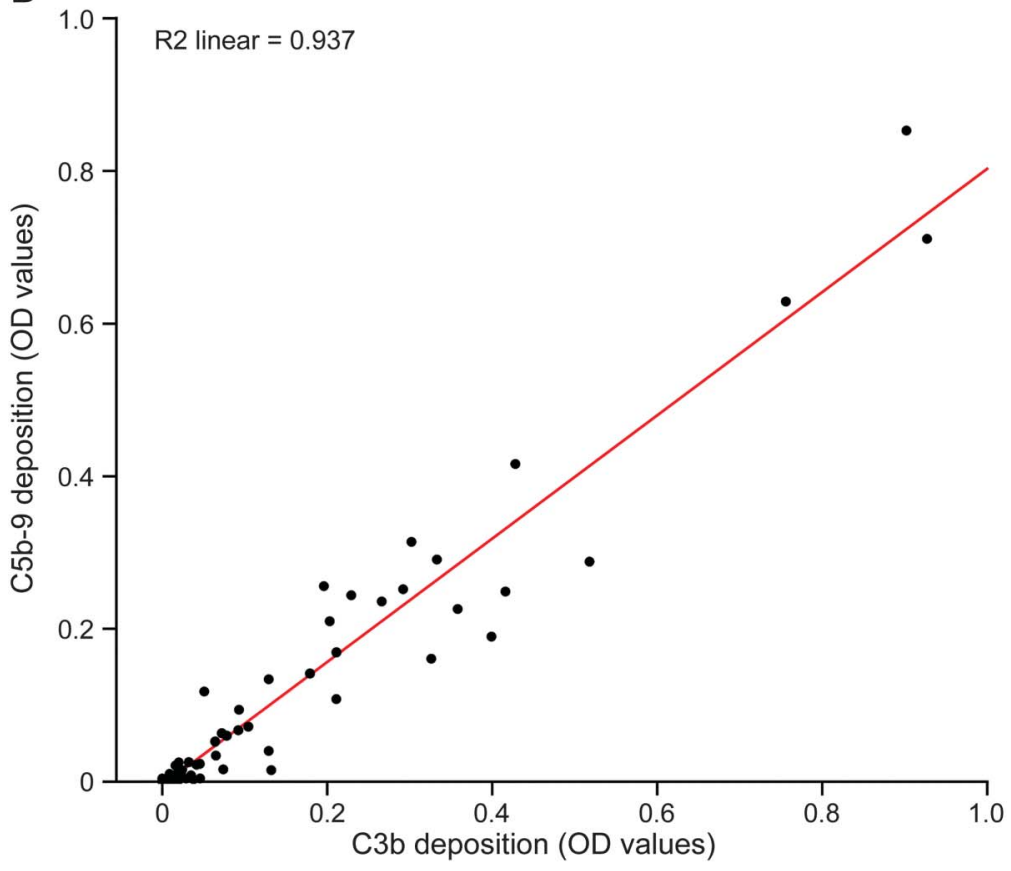

(A) Association between lgM anti-GM1 antibody titers and complement deposition. Data are expressed as median optical density (OD) values of $\mathrm{C} 3 \mathrm{~b}$ and $\mathrm{C} 5 \mathrm{~b}-9$ deposition; the error bars represent the $95 \%$ confidence interval. (B) Correlation between deposition of complement components $\mathrm{C} 3 \mathrm{~b}$ and $\mathrm{C} 5 \mathrm{~b}-9$.

pathway activity with the degree of axonal loss (mild $p=0.17$, moderate $p=0.03$, severe $p=0.07$ ) (figure 3A).

Complement-activating capacity of anti-GM1 IgM antibodies, defined as the deposition of complement component $\mathrm{C} 3 \mathrm{~b}$, was also higher in the patients with severe weakness $(p=0.03)$ and axon loss $(p=$ $0.01)$. There was no difference in complementactivating capacity of anti-GM1 IgM antibodies between patients with minor, mild, or moderate symptoms (figure 3B).

MBL2 genotypes, serum MBL concentration, and intrinsic lectin pathway were not associated with disease severity. Number of years without IVIg treatment, which is a known prognostic factor, ${ }^{2}$ was significantly associated with a more severe outcome.

DISCUSSION The results of this study underline the importance of antibody-complement interaction in MMN pathogenesis and suggest that both complement-activating capacity of anti-GM1 IgM antibodies and high innate classical pathway activity are risk factors for unfavorable outcome in MMN. Previous studies have shown that anti-GM1 IgM antibodies in sera from patients with MMN have complement-activating properties. ${ }^{13,14}$ This study is unique in that we addressed both complement and antibody activity in relation to disease characteristics.

Our findings fit into a model of MMN pathogenesis in which antibody-mediated complement deposition at the nodes of Ranvier is a crucial step..$^{8,9,12}$ Although complement deposition in motor nerves of patients with MMN has not been studied in detail, experimental studies have identified complement deposition as an important pathogenic mechanism that causes disruption of the ultrastructure at the nodes of Ranvier and paranodes, in particular the clustering of ion channels. ${ }^{12}$ Our data confirmed that anti-GM1 IgM antibodies trigger complement deposition only via the classical pathway. ${ }^{13,14}$ Both high innate classical pathway activity and complement-activating capacity of anti-GM1 antibodies were associated with severe weakness and axonal loss, suggesting that patient characteristics that may promote complement deposition in nerves influence outcome. Whether a similar pathogenic mechanism underlies MMN in patients without apparent anti-GM1 IgM antibody titers remains unknown. Recent reports have suggested that the subgroup of patients without anti-GM1 antibodies may be smaller than previously assumed when more sensitive methodology is used, but these studies have also consistently shown that a subgroup of patients completely lack anti-GM1 IgM. ${ }^{26,27}$ We did not find evidence for a role of the MBL pathway of complement in MMN pathogenesis, in contrast to a previous report in GBS. ${ }^{15}$ Innate activity of the MBL pathway and MBL concentrations were similar in patients and controls, antiGM1 antibodies did not activate the MBL pathway in vitro, and there was no association with MBL2 genotypes.

The use of IVIg maintenance therapy by the majority of patients with MMN at the time of 

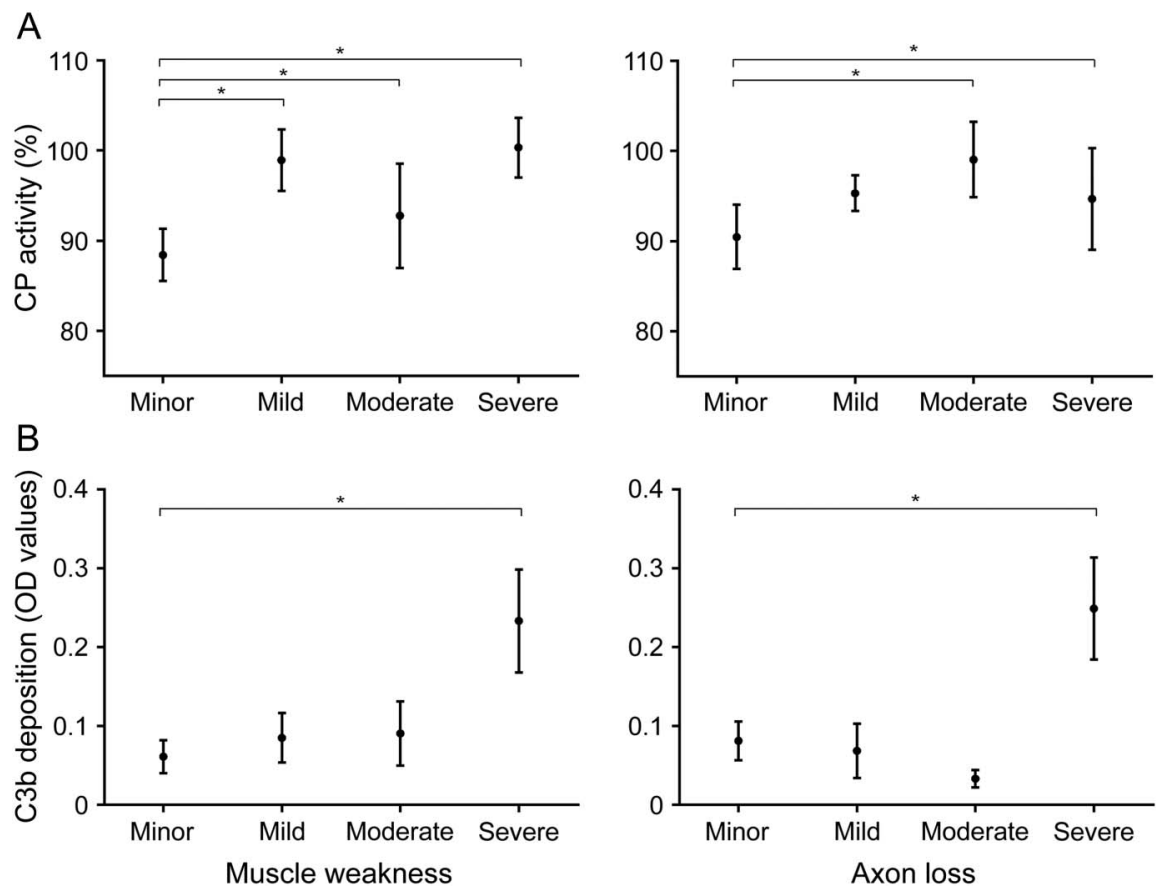

(A) Association between high innate classical pathway (CP) activity and degree of muscle weakness and axon loss. Innate CP activity was higher in patients with mild $(p=0.006)$, moderate $(p=0.02)$, and severe weakness $(p=0.003)$ compared with those with minor weakness. Axon loss was also more pronounced in patients with higher innate CP activity (mild $p=0.17$, moderate $p=0.03$, severe $p=0.07$ ). (B) Association between activation of the complement system by IgM anti-GM1 antibodies and degree of muscle weakness and axon loss. Anti-GM1 IgM complement-activating capacity, defined by the deposition of complement component C3, was significantly higher in the patients with severe weakness $(p=0.03)$ and axonal loss $(p=0.01)$ compared with those with minor weakness or axon loss. Data were analyzed in a multivariate model with sex, conduction block, age at onset, number of years untreated, and IgG concentration included as covariates. Data are presented as mean with SEM. *p $<0.05$. OD = optical density.

venapuncture is a potential weakness of this study. Although there was no inverse correlation of $\operatorname{IgG}$ concentrations with complement activity or differences in complement activity between patients with and without IVIg, we cannot exclude the possibility that IVIg maintenance therapy changed innate complement activity. ${ }^{13,14}$ Inclusion of only treatment-naive patients was not feasible due to the low incidence of $\mathrm{MMN}^{2}$

Experimental complement inhibition attenuated disease course in animal models of anti-ganglioside antibody-mediated neuropathies. ${ }^{28-30}$ Although IVIg exerts multiple immunomodulatory effects, ${ }^{31} \mathrm{IVIg}$ efficacy may be at least partially explained by both complement inhibition at systemic levels and attenuation of complement deposition in nerves..$^{13,14,32-34} \mathrm{It}$ has not been established whether currently used IVIg doses and treatment frequencies optimally attenuate complement activity. IVIg doses and pharmacokinetics differ between patients, which could cause interindividual differences in complement inhibition at equivalent IVIg doses. ${ }^{2,35}$ Our data may suggest that patients with relatively high levels of innate complement activity or antibodies with pronounced complement-activating properties could benefit from higher IVIg dosing or additional alternative complement inhibitory treatment strategies. Nafamostat mesilate, a synthetic serine protease inhibitor that has been successfully tested in the GBS rabbit model, ${ }^{28}$ and monoclonal antibodies that target complement components of the classical or terminal pathway are possible candidate drugs. Adjunctive treatment with the C5-specific monoclonal antibody eculizumab led to small improvements in motor performance in some patients with MMN. ${ }^{36}$ The relatively disappointing results from this trial may suggest that there are other pathogenic mechanisms besides MAC deposition in MMN, but it cannot be excluded that deposition of C3, which is not blocked by eculizumab, is sufficient to cause ultrastructural alterations at the nodes of Ranvier. Alternatively, eculizumab infusion may not cause full C5 depletion in the peripheral nervous system or may fail to antagonize local production of $\mathrm{C} 5$ by Schwann cells. Larger randomized controlled trials in patients with both GBS and MMN are needed to further clarify these issues. ${ }^{37,38}$

\section{AUTHOR CONTRIBUTIONS}

L. Vlam: drafting/revising the manuscript for content, analysis or interpretation of data, acquisition of data, statistical analysis. E.A. Cats: drafting/revising the manuscript for content, acquisition of data. 
O. Harschnitz: drafting/revising the manuscript for content, analysis or interpretation of data. M.D. Jansen: drafting/revising the manuscript for content, acquisition of data. S. Piepers: drafting/revising the manuscript for content, acquisition of data. J.H. Veldink: drafting/revising the manuscript for content, statistical analysis. H. Franssen: drafting/ revising the manuscript for content. A.C.J. Stork: drafting/revising the manuscript for content, acquisition of data. E. Heezius: drafting/revising the manuscript for content, acquisition of data. S.H.M. Rooijakkers: drafting/revising the manuscript for content, acquisition of data. B.L. Herpers: drafting/revising the manuscript for content, acquisition of data. J.A. van Strijp: drafting/revising the manuscript for content. L.H. van den Berg: drafting/revising the manuscript for content, study concept or design, analysis or interpretation of data, obtaining funding, study supervision or coordination. W.L. van der Pol: drafting/revising the manuscript for content, study concept or design, analysis or interpretation of data, obtaining funding, study supervision or coordination.

\section{STUDY FUNDING}

This study was supported by the Prinses Beatrix Spierfonds.

\section{DISCLOSURE}

L. Vlam, E.A. Cats, O. Harschnitz, M.D. Jansen, and S. Piepers report no disclosures. J.H. Veldink has received travel funding and/or speaker honoraria from Baxter. H. Franssen received travel funding from Baxter, is on the editorial board for Clinical Neurophysiology, and received research support from Prinses Beatrix Spierfonds. A.C.J. Stork, E. Heezius, S.H.M. Rooijakkers, and B.L. Herpers report no disclosures. J.A. van Strijp received research support from Vaccines \& Evasion Min. of Veterinary Affairs, Finnish Cult. Foundation, N-Norway Reg. Health Auth., Utrecht Life Sciences, and Eurostars E! L.H. van den Berg received travel grants and consultancy fees from Baxter; served on scientific advisory boards for the Prinses Beatrix Spierfonds, the Thierry Latran Foundation, Biogen Idec, and Cytokinetics; served on the editorial board of Amyotrophic Lateral Sclerosis and the Journal of Neurology, Neurosurgery \& Psychiatry; and received research support from the Prinses Beatrix Spierfonds, Netherlands ALS Foundation, VSB Fonds, Adessium Foundation, and the European Union. W.L. van der Pol received travel grants from Baxter International Inc. and research support from the Prinses Beatrix Spierfonds and Stichting Spieren voor Spieren. Go to Neurology.org/nn for full disclosure forms.

Received December 5, 2014. Accepted in final form March 11, 2015.

\section{REFERENCES}

1. Vlam L, van der Pol WL, Cats EA, et al. Multifocal motor neuropathy: diagnosis, pathogenesis and treatment strategies. Nat Rev Neurol 2011;8:48-58.

2. Cats EA, van der Pol WL, Piepers $S$, et al. Correlates of outcome and response to IVIg in 88 patients with multifocal motor neuropathy. Neurology 2010;75:818-825.

3. Cats EA, Jacobs BC, Yuki N, et al. Multifocal motor neuropathy: association of anti-GM1 IgM antibodies with clinical features. Neurology 2010;75:1961-1967.

4. Kokubun N, Nishibayashi M, Uncini A, Odaka M, Hirata K, Yuki N. Conduction block in acute motor axonal neuropathy. Brain 2010;133:2897-2908.

5. Yuki N. Acute motor axonal neuropathy and multifocal motor neuropathy: more in common than not. Muscle Nerve 2013;48:693-695.

6. Willison HJ, Yuki N. Peripheral neuropathies and antiglycolipid antibodies. Brain 2002;125:2591-2625.

7. Vlam L, van den Berg LH, Cats EA, Piepers S, van der Pol WL. Immune pathogenesis and treatment of multifocal motor neuropathy. J Clin Immunol 2012;33(suppl 1):S38-S42.

8. Yuki N, Yamada M, Koga M, et al. Animal model of axonal Guillain-Barré syndrome induced by sensitization with GM1 ganglioside. Ann Neurol 2001;49:712-720.
9. van Sorge NM, Yuki N, Jansen MD, et al. Leukocyte and complement activation by GM1-specific antibodies is associated with acute motor axonal neuropathy in rabbits. J Neuroimmunol 2007;182:116-123.

10. Susuki K, Baba H, Tohyama K, et al. Gangliosides contribute to stability of paranodal junctions and ion channel clusters in myelinated nerve fibers. Glia 2007;55:746-757.

11. Uncini A, Notturno F, Capasso M. Natura non facit saltus in anti-ganglioside antibody-mediated neuropathies. Muscle Nerve 2013;48:484-487.

12. Susuki K, Rasband MN, Tohyama K, et al. Anti-GM1 antibodies cause complement-mediated disruption of sodium channel clusters in peripheral motor nerve fibers. J Neurosci 2007;27:3956-3967.

13. Piepers S, Jansen MD, Cats EA, van Sorge NM, van den Berg LH, van der Pol WL. IVIg inhibits classical pathway activity and anti-GM1 IgM-mediated complement deposition in MMN. J Neuroimmunol 2010;229:256-262.

14. Yuki N, Watanabe H, Nakajima T, Spath PJ. IVIG blocks complement deposition mediated by anti-GM1 antibodies in multifocal motor neuropathy. J Neurol Neurosurg Psychiatry 2011;82:87-91.

15. Geleijns K, Roos A, Houwing-Duistermaat JJ, et al. Mannose-binding lectin contributes to the severity of GuillainBarré syndrome. J Immunol 2006;177:4211-4217.

16. Van den Berg-Vos RM, Franssen H, Wokke JH, Van Es HW, Van den Berg LH. Multifocal motor neuropathy: diagnostic criteria that predict the response to immunoglobulin treatment. Ann Neurol 2000;48:919-926.

17. Van Asseldonk JT, Van den Berg LH, Van den BergVos RM, Wieneke GH, Wokke JH, Franssen H. Demyelination and axonal loss in multifocal motor neuropathy: distribution and relation to weakness. Brain 2003;126: 186-198.

18. Gabolde M, Muralitharan S, Besmond C. Genotyping of the three major allelic variants of the human mannosebinding lectin gene by denaturing gradient gel electrophoresis. Hum Mutat 1999;14:80-83.

19. Herpers BL, Endeman H, de Jong BA, et al. Acute-phase responsiveness of mannose-binding lectin in communityacquired pneumonia is highly dependent upon MBL2 genotypes. Clin Exp Immunol 2009;156:488-494.

20. Madsen HO, Garred P, Thiel S, et al. Interplay between promoter and structural gene variants control basal serum level of mannan-binding protein. J Immunol 1995;155: 3013-3020.

21. Garred P, Larsen F, Madsen HO, Koch C. Mannose-binding lectin deficiency-revisited. Mol Immunol 2003;40: 73-84.

22. Petersen SV, Thiel S, Jensen L, Steffensen R, Jensenius JC. An assay for the mannan-binding lectin pathway of complement activation. J Immunol Methods 2001;257:107-116.

23. Roos A, Bouwman LH, Munoz J, et al. Functional characterization of the lectin pathway of complement in human serum. Mol Immunol 2003;39:655-668.

24. Roos A, Nauta AJ, Broers D, et al. Specific inhibition of the classical complement pathway by C1q-binding peptides. J Immunol 2001;167:7052-7059.

25. Van Asseldonk JT, Van den Berg LH, Kalmijn S, et al. Axon loss is an important determinant of weakness in multifocal motor neuropathy. J Neurol Neurosurg Psychiatry 2006;77:743-747.

26. Pestronk A, Choksi R, Blume G, Lopate G. Multifocal motor neuropathy: serum IgM binding to a GM1 
ganglioside-containing lipid mixture but not to GM1 alone. Neurology 1997;48:1104-1106.

27. Galban-Horcajo F, Fitzpatrick AM, Hutton AJ, et al. Antibodies to heteromeric glycolipid complexes in multifocal motor neuropathy. Eur J Neurol 2012;20:62-70.

28. Phongsisay V, Susuki K, Matsuno K, et al. Complement inhibitor prevents disruption of sodium channel clusters in a rabbit model of Guillain-Barré syndrome. J Neuroimmunol 2008;205:101-104.

29. Willison HJ, Halstead SK, Beveridge E, et al. The role of complement and complement regulators in mediating motor nerve terminal injury in murine models of Guillain-Barré syndrome. J Neuroimmunol 2008;201-202: 172-182.

30. Halstead SK, Zitman FM, Humphreys PD, et al. Eculizumab prevents anti-ganglioside antibody-mediated neuropathy in a murine model. Brain 2008;131: 1197-1208.

31. Dalakas MC. Intravenous immunoglobulin in autoimmune neuromuscular diseases. JAMA 2004;291:23672375.

32. Lutz HU, Stammler P, Bianchi V, et al. Intravenously applied $\operatorname{IgG}$ stimulates complement attenuation in a complement-dependent autoimmune disease at the amplifying C3 convertase level. Blood 2004;103:465-472.

33. Yuki N, Kuwabara S. Axonal Guillain-Barré syndrome: carbohydrate mimicry and pathophysiology. J Peripher Nerv Syst 2007;12:238-249.

34. Nishimoto Y, Koga M, Kamijo M, Hirata K, Yuki N. Immunoglobulin improves a model of acute motor axonal neuropathy by preventing axonal degeneration. Neurology 2004;62:1939-1944.

35. Vlam L, Cats EA, Willemse E, et al. Pharmacokinetics of intravenous immunoglobulin in multifocal motor neuropathy. J Neurol Neurosurg Psychiatry 2014;85:1145-1148.

36. Fitzpatrick AM, Mann CA, Barry S, Brennan K, Overell JR, Willison HJ. An open label clinical trial of complement inhibition in multifocal motor neuropathy. J Peripher Nerv Syst 2011;16:84-91.

37. Nobile-Orazio E, Gallia F. Multifocal motor neuropathy: current therapies and novel strategies. Drugs 2013;73: 397-406.

38. Umapathi T, Hughes RA, Nobile-Orazio E, Leger JM. Immunosuppressant and immunomodulatory treatments for multifocal motor neuropathy. Cochrane Database Syst Rev 2012;4:CD003217. 


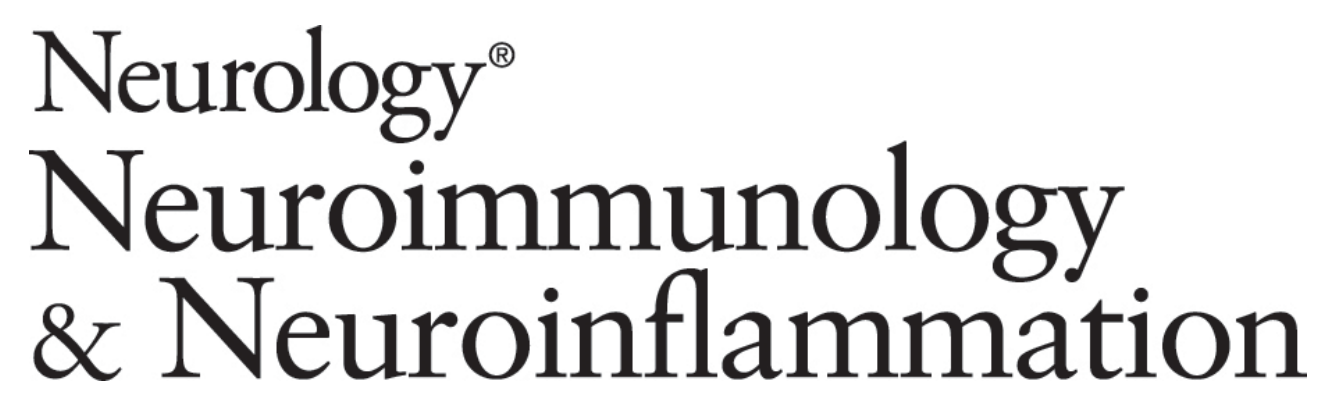

Complement activity is associated with disease severity in multifocal motor neuropathy Lotte Vlam, Elisabeth A. Cats, Oliver Harschnitz, et al.

Neurol Neuroimmunol Neuroinflamm 2015;2;

DOI 10.1212/NXI.0000000000000119

This information is current as of June 25, 2015

Neurol Neuroimmunol Neuroinflamm is an official journal of the American Academy of Neurology.

Published since April 2014, it is an open-access, online-only, continuous publication journal. Copyright $\odot$ 2015 American Academy of Neurology. All rights reserved. Online ISSN: 2332-7812.

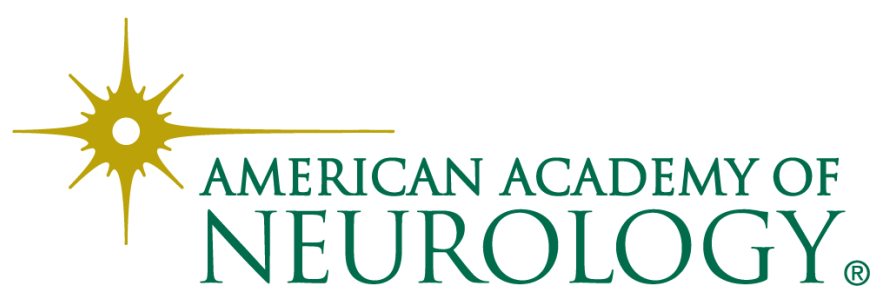




\section{Updated Information \&} Services

\section{Supplementary Material}

\section{References}

Citations

Subspecialty Collections

Permissions \& Licensing

Reprints including high resolution figures, can be found at: http://nn.neurology.org/content/2/4/e119.full.html

Supplementary material can be found at: http://nn.neurology.org/content/suppl/2015/06/25/2.4.e119.DC1

This article cites 38 articles, 8 of which you can access for free at: http://nn.neurology.org/content/2/4/e119.full.html\#\#ref-list-1

This article has been cited by 2 HighWire-hosted articles: http://nn.neurology.org/content/2/4/e119.full.html\#\#otherarticles

This article, along with others on similar topics, appears in the following collection(s):

\section{All Immunology}

http://nn.neurology.org//cgi/collection/all_immunology

All Neuromuscular Disease

http://nn.neurology.org//cgi/collection/all_neuromuscular_disease Peripheral neuropathy

http://nn.neurology.org//cgi/collection/peripheral_neuropathy

Information about reproducing this article in parts (figures,tables) or in its entirety can be found online at:

http://nn.neurology.org/misc/about.xhtml\#permissions

Information about ordering reprints can be found online:

http://nn.neurology.org/misc/addir.xhtml\#reprintsus

Neurol Neuroimmunol Neuroinflamm is an official journal of the American Academy of Neurology.

Published since April 2014, it is an open-access, online-only, continuous publication journal. Copyright $\odot$ 2015 American Academy of Neurology. All rights reserved. Online ISSN: 2332-7812.

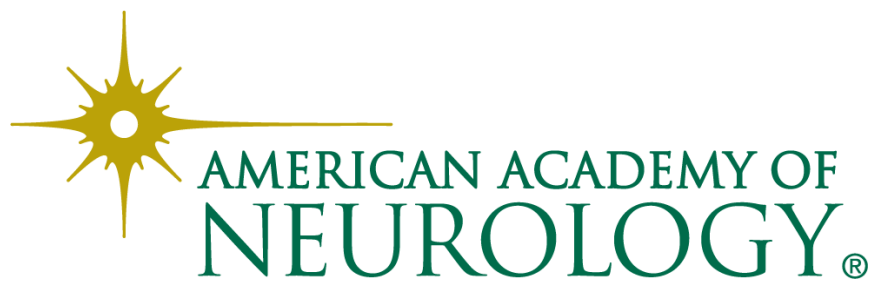

